\title{
船舶の混合交通にむける交通量換算係 数について
}

\author{
田中 健一*.山田一成* \\ On the Epuivalent Number. of Vessles of Various Size in \\ the Marine Traffic
}

K. Tanaka and K. Yamada

\begin{abstract}
The observation in the separation of various size of vessels whose lengths are different considerably was carried out with a mm wave radar and a multiexposure camera, and the following results were obtained.

The size of effective dowain is given as

$$
r_{i j}=\sqrt{\left(r_{i i}{ }^{2}+r_{j j}{ }^{2}\right) / 2}, \quad \mathrm{si} j=\sqrt{\left(S_{i i}{ }^{2}+S_{j j}{ }^{2}\right) / 2}
$$

where $r_{p q}$ and $S_{p q}$ are the length and width of the effective domain respectively and subscripts, $p$ and $q$, refer to preceeding and following vessels, respectively.

The ratio of the area of effective domain of a large sized vessel and that of the standard one is defined as "the equivalent number." Above equation gives that the equivalent number is proportional to the square of the length of vessel.
\end{abstract}

\section{1. は し がき}

狭水道などにおける船舶の輻輳に伴なう海上交通工学研究の必要性は，いまさら言を俟たない ところである。著者らは，この研究の分野で交通容量という観点から問題解決へのアプローチを 試みてきた[1]，[2]。ここでは，先に発表した閉塞領域に及ぼす湖流の影響に関する研究 [3] に引きつづき, 可能交通容量の第 2 段階として, この大小船混在時における航行現象のらち, 同 航の場合の解析を行ない，一応の結論を得たので，以下に報告する。

なお，この問題に関する研究はいままで一部取扱われているが $[4]$, 明確な解析はなされてい ないようである。

\section{2. 観測}

わが国で最も大型船の交通量の多い浦賀水道において昭和 42 年 8 月と昭和 43 年 8 月の 2 回にわ たつて観測を赛施たし。観測には前回発表のものと同様, ミリ波レーダ（沖電気工 業(株)製， $\mathrm{CDSH}$ - $4 \mathrm{~A}$ 型，9.2mm波）と当所で開発したプログラム・レーダ連続撮影装置を用い，観音埼

*船舶技術研究所（東京都三鷹市新川 6-38-1） 
航路標識事務所（海面上約 $46 \mathrm{~m}$ 地点）飞観測所を設置した。本観測に预ける観測装置使用の状況 を図 1 亿，また観測により得られたレーダ写真の 1 コマを図 2 亿示す。さらに，観測実施要項を

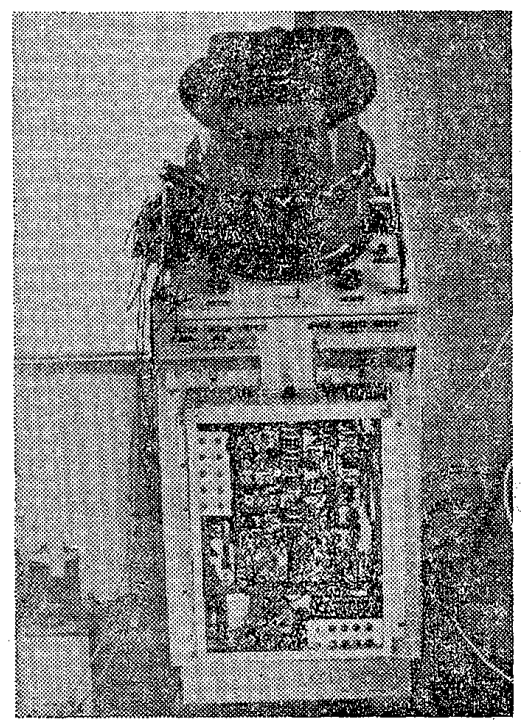

図 1 観測装置使用の状況

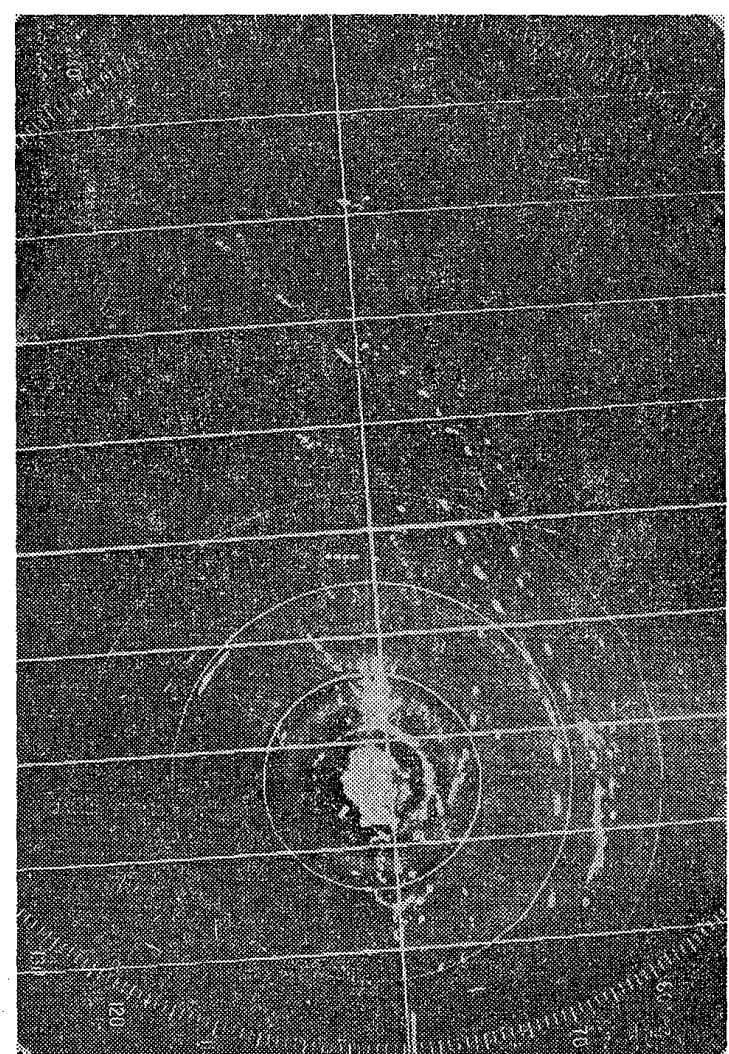

図 2 レーダ軍真の 1 コマ

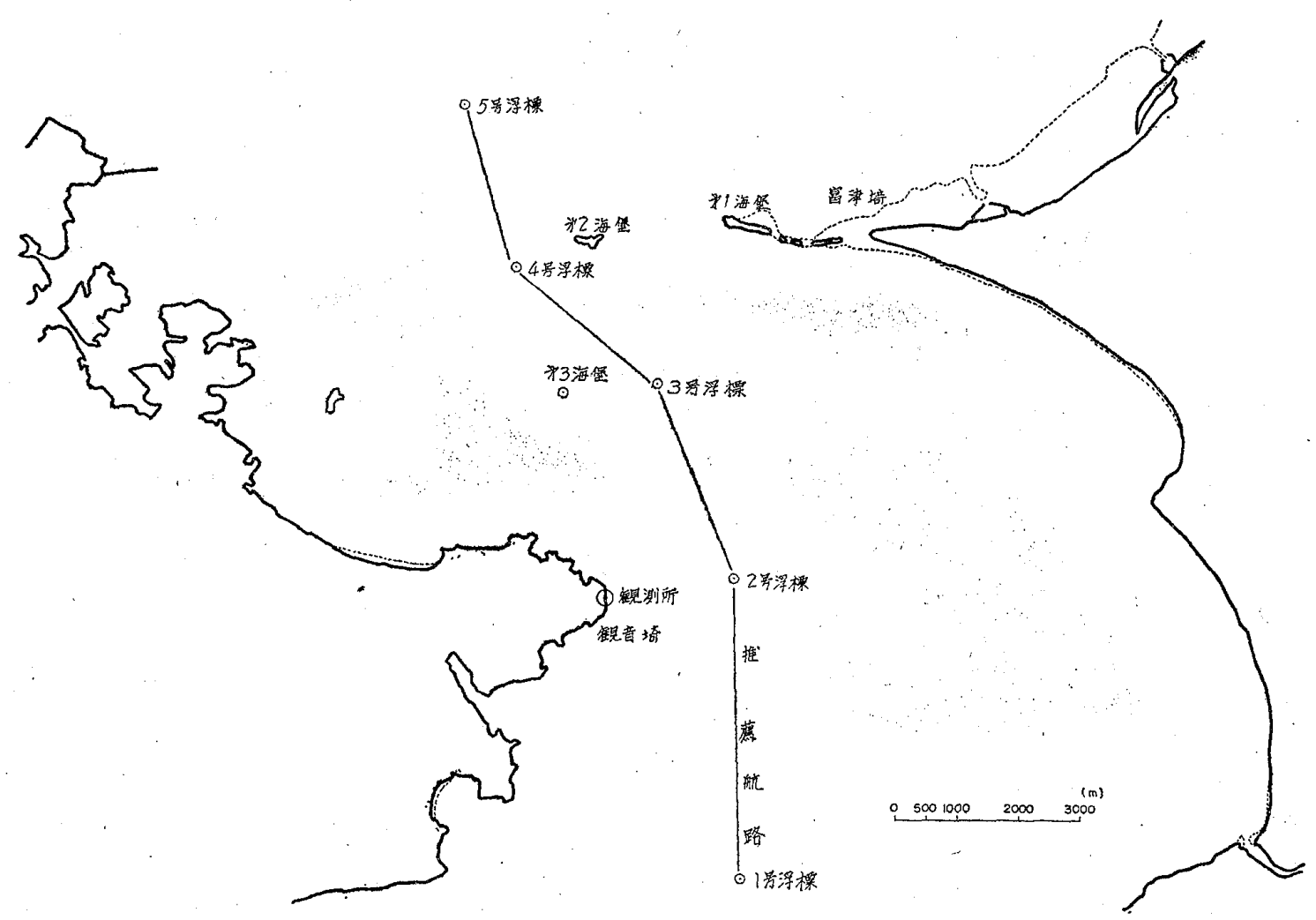

図 3 観測場所付近の見取り図 
表 1 観 測，実 施 要 項

\begin{tabular}{|c|c|c|c|}
\hline 観 測 & 期 & 間 & 観 測 対 象 水 域 \\
\hline 第 1 次 & $\stackrel{\text { 昭 } 42.8 .11}{\sim} 8.11$ & $\begin{array}{l}12: 00 \\
12: 00\end{array}$ & 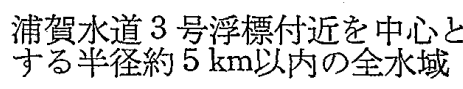 \\
\hline 第 2 次 & 昭 43.8 .5 & $\begin{array}{l}12: 00 \\
12: 00\end{array}$ & 同 \\
\hline
\end{tabular}

表 1 に，観測場所付近の見取り図を図 3 に示す。

観測は，第 1 次，第 2 次とも比較的天候に恵まれ，かつ観測装置もほぼ順調に作動し，一部を 除いて良好な結果が得られた。

\section{3. 観測結果とその考察}

1 分間ごとに約 3 秒露出し， 6 分間をフイルム 1 コマに収めるプログラム・レーダ連続撮影装 置を用いて得られた観測フイルムは，前回と同様，フイルム\%リーダにかけられ，これから航跡 図が作成された。さらに，これょり先行船に対する後続船の1 分間隔ごとの相対位置 (Y), 距離 間隔 $(X))$ を 1 組について 5 点ずつ読取つた。また，これに対応する 2 船の長さおよび速力を求 めた。この場合の観測精度の䛊差は長さで士10m，時間で士 $3 \mathrm{sec}$ ぐらいと推定された。ここで， 先行船および後続船の大きさを便宜的に表 2 亿示されるような範囲を定めて小型船(A)，中型船 (B)斿よび大型船(C)に区分けする。

表 3 船舶の大きさの分類

\begin{tabular}{|l|c|c|c|}
\hline 分 類 & 記号 & 全長の笨囲 $(\mathrm{m})$ & 総トン数のおおよその範囲 $(\mathrm{t})$ \\
\hline 小 型 船 & $\mathrm{A}$ & $30 \sim 50$ & $100 \sim 500$ \\
\hline 中 型 船 & $\mathrm{B}$ & $60 \sim 100$ & $500 \sim 3,000$ \\
\hline 大 型 船 & $\mathrm{C}$ & $110 \sim 200$ & $3,000 \sim 20,000$ \\
\hline
\end{tabular}

精度の点汃ら $10 \mathrm{~m}$ 単位にまるめてある。

次に，船の大きさの区分けに従つて相対位置のデータを組分けする。すなわち，船の大きさ $\mathrm{A} ， \mathrm{~B}, \mathrm{C}$ の先行船に対する $\mathrm{A} ， \mathrm{~B}, \mathrm{C}$ の大きさの後続船の組合せ 9 個について相対位置分布図 を求める。その結果を図 4 に示す。図中の $A A ; A B ; \cdots \cdots \cdots$ 䊗行船 $\mathrm{A}$, 後続船 $A$; 先行船 $A$, 後 続船 $B, \cdots \cdots \cdots$ 宗す。また， $\overline{L_{A}}, \overline{L_{B}}, \cdots \cdots$ は上段が先行船の長さの平均 $(\mathrm{m})$, 下段が 後続船の長さ の平均 $(\mathrm{m})$ を表わし, 前述のように $Y$ は先行船に対する後続船の距離 $(\mathrm{m})|X|$ は同様間隔 $(\mathrm{m})$ を 表わす。この場合は，前報と同様左側のデータを右側に重ねて絶対值記号を付してある。枠の中

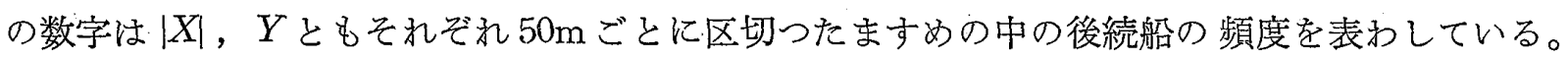
この頻度極大のところをつないで閉塞領域を求めることができる。図中の折線はこのようにして 求めた閉塞領域の境界線を示す。この 9 組の閉塞領域をみると，従来加ら言われているよらに， その大きさに対する船の長さの依存性が明確にでていて，小型船どうしの組合せ (AA) や小型船 と中型船の組合せ $(\mathrm{AB}, \mathrm{BA})$ は大型船どうしの組合せ $(\mathrm{CC})$ や大型船と中型船の組合せ $(\mathrm{CB}$, BC）に比べて閉塞領域が小さい。これらの関係を定量的に求めたものが図 5 で, 縦・横軸とも対 数目盛を施し, 縦軸は閉塞領域の進行方向の長さ $r(\mathrm{~m})$ とこれに直角方向の幅 $\mathrm{s}(\mathrm{m})$ とを示し, 横軸法添字 $p$ 先行船, $q$ 後続船とし, それぞれの長さを $L_{p}, L_{q}$ で表をしたときの $\sqrt{\left(\overline{\left.L_{p}{ }^{2}+L_{q}{ }^{2} / 2\right)}\right)}$ 

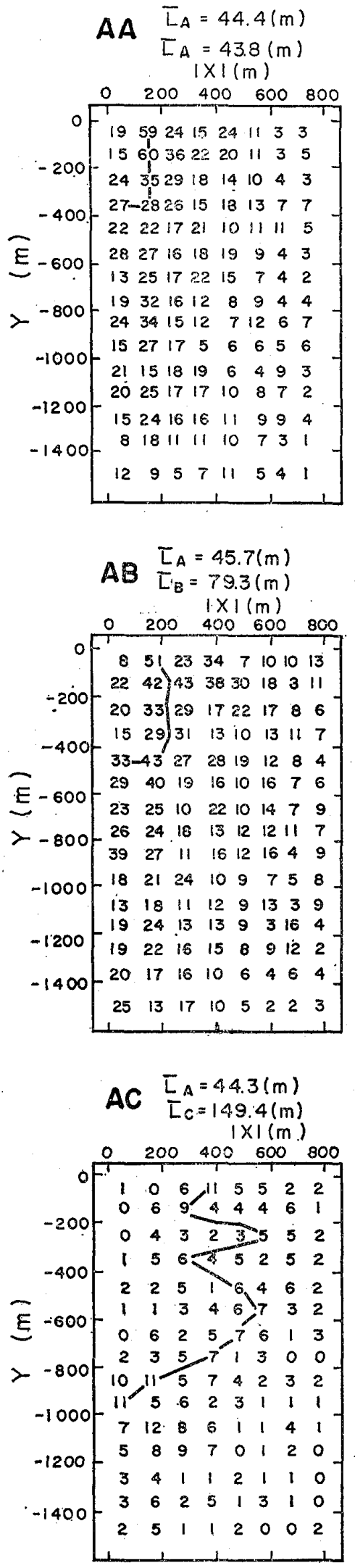


図 4 後続船の相対位置分布図 (50mますめ) 


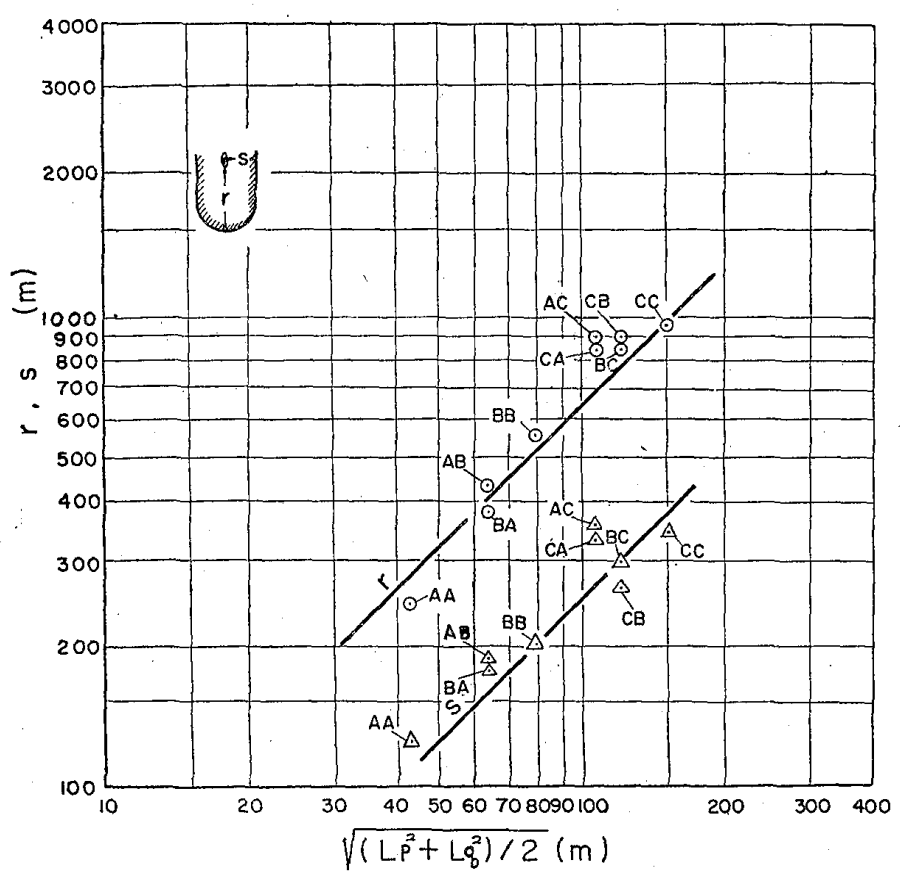

図 $5 r . s$ と $\sqrt{\left(L_{p}^{2}+L_{q}^{2}\right) / 2}$ の関係
示すものである。いま図 $40 \overline{L_{A}}, \overline{L_{A}} ; \overline{L_{A}}$, $\overline{L_{B}} \cdots \cdots$ を $L_{p}, L_{q}$ に与えて，r. $s$ を表わ すとプロツトのようになる。図中の $A A$ ， $B B$ 扝よび $C C$ 注従来の基本交通容量を 対象とした先行船と後続船の大きさの等 しい場合の閉塞領域の大きさを表わす。 これらの点は $r . s$ とも図示のようにほぼ 直線に萧り，その直線が右上がり，执よ そ $45^{\circ}$ となつて $V^{\prime}\left(\overline{\left.L_{p}{ }^{2}+L_{q}^{2}\right) / 2}=L_{i}(i=\right.$ $A, B, C)$ であるから，r.s 注 $L_{i}$ に比例し，

$$
r \doteqdot 6.5 L_{i}, s \fallingdotseq 2.5 L_{i}
$$

となる。これは，断片的に求めた従来の 值にほぼ等しいこと亦している。次に $A B, B A$ は $A A$ と $B B$ の間で，また， $B C, C B$ は $B B$ と $C C$ の閒で，それぞれ ほぼこの直線に乗つていることが分る。 しかし，AC と $C A$ とはいくぶんこの直 線から離れているようである。いま，大小船混在時の閉塞領域の長さを $r_{p q}$ ，幅を $s_{p q}$ とすると， 近似的に

$$
\begin{aligned}
& r_{i j}=\sqrt{\left(r_{i i}{ }^{2}+r_{j j}{ }^{2}\right) / 2} \\
& s_{i j}=\sqrt{\left(S_{i i}{ }^{2}+s_{j j}{ }^{2}\right) / 2} \\
& (i, j=A, B, C)
\end{aligned}
$$

が成立つとして差支えない。

混合交通に扔ける交通量を統一的に取扱う換算交通量を算出する場合，その換算係数は閉塞領 域の面積比 $r_{i j} s_{i j} / r_{o} s_{o}$ をむつて表現されるべきで，前の関係式が一般に成立つをすれね゙，混合の 割合に関係なく, この換算係数 $E$ は

$$
E=r_{i i} s_{i i} / r_{o} s_{o}=\left(L_{i} / L_{o}\right)^{2}
$$

となる(付録参照)。ただし， $r_{o} s_{o}$ およよ゙ $L_{o}$ は標準船の閉塞領域の長さ，幅および船の長さを示 すものである。従つて，たとえば船の長さが標準船の 2 倍の船は換算係数 $4 ， 3$ 倍の船核算係 数 9 といらことになる。

なお，参考までに図 4 に収録されているデータの総数について船の大きさ別の平均速力执よび 標準偏差を表で示すと表 3 のようになる。

表 3 観測船舶の全長と平均速力の関倸

\begin{tabular}{|cc|c|c|c|c|}
\hline 分 & 類 & 全長の平均 $(\mathrm{m})$ & 全長の標準偏差 $(\mathrm{m})$ & 平均速力 $(\mathrm{kt})$ & 速力の標準偏差 $(\mathrm{kt})$ \\
\hline 小. 型 & 船 & 45.0 & 8.3 & 10.0 & 3.5 \\
\hline 中. 型 & 船 & 80.6 & 12.6 & 10.9 & 2.9 \\
\hline 大 . 型 & 船 & 150.1 & 26.7 & 14.0 & 3.8 \\
\hline
\end{tabular}


45 年 12 月

\section{4. む す び}

浦賀水道で実施したミリ波レーダの海上交通実態観測結果から，長さが 30〜 200m の範囲の船 について，大小船混在時の閣塞領域の状況を近似的に把握し(1)式を導いた。次に，この関係式か ら一般の大きさの船の混合交通における換算係数が(2)式で表わされること，すなわち，船の長さ の 2 乗に比例することを示した。

本観測は海上保安庁の後援のもとに行なわれたものであり, また観測の実施に当つては日本レ ーダーサービス(株)からも多くの援助を受けた。両者に対し，あつく感謝の意を表する次第であ る。さらにここ意見をよせられた電子航法研究所の藤井弥平部長に謝意を表したいと思う。

\section{参 考 文 献}

[1] 藤井, 田中, 渡辺, 山田 :, 船舶の闒塞領域について, 日本航海学会誌, 35号 (1968), pp. 71 76

〔2]藤井, 田中, 山田, 沢井, 金丸：中型船の閉塞領域について, 日本航海学会誌, 38号(1967), pp. 15 20

[3]田中, 藤井 : 航行船舶の閉塞領域に及ぼす潮流の影響について, 日本航海学会誌, 41号 (1969), pp. 31 39

[4]東京商船大学船舶畺航技術研究会：浦賀水道船舶交通実態調查報告書 (1967), pp. 120 126

\section{付 録}

\section{混合割合に関係なく換算係数が一定であることの証明}

I

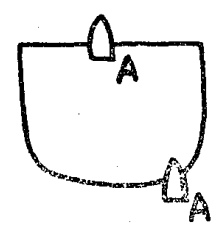

II
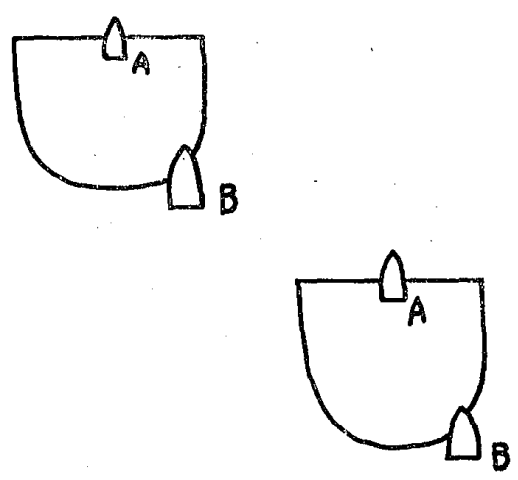

付図 1. A B 2 船の結合のしかた

いま簡単のために標準船を $A$ ，対象船を $B$ とし，この $A, B 2$ 種の大きさの船の組合せだけを考えることにす る。添字は本文の約束に従うとし，

$L_{B}=k L_{A}, r_{A A}=C_{r} \cdot L_{A}, s_{A A}=C_{s} \cdot L_{A}\left(k, C_{r}, C_{s}\right.$ 注定 数）とすれば面積一定の水域に $A 2$ 隻, $B 2$ 隻が航行す るとき付図 1 ように $A$ と $A ; B$ と $B$ の結びつきの場合 (I) と $A$ と $B ; A$ と $B$ の結びつきの場合 (II) とが考 えられる。川の場合， $A, B$ いずれが先行船であつても 本文に従つて同一の関係が成立つとする。

I，IIの場合の換算交通量をそれぞれ $Q_{\mathrm{I}}, Q_{\text {II }}$ とすれ ば

$$
\begin{aligned}
Q_{\mathrm{I}}= & \frac{2 r_{A A} s_{A A}+2 r_{B B} \cdot s_{B B}}{r_{A A} \cdot s_{A A}}=\frac{2 C_{r} \cdot C_{s} \cdot L_{A}+2 \cdot k^{2} C_{r} \cdot C_{s} \cdot L_{A}}{C_{r} \cdot C_{s} \cdot L_{A}^{2}} \\
& =2\left(1+k^{2}\right) \ldots \ldots \ldots \ldots \ldots \ldots \ldots(\mathrm{A}-1) \\
Q_{\mathrm{II}}= & \frac{2 \cdot 2 r_{A B} s_{A B}}{r_{A A} \cdot s_{A A}}=\frac{4 \sqrt{\frac{r_{A A}{ }^{2}+r_{B B}}{2}} \cdot \sqrt{\frac{s_{A A}+s_{B B}}{2}}}{C_{r} \cdot C_{s} \cdot L_{A}^{2}} \\
& =2\left(1+k^{2}\right) \cdots \ldots \ldots \ldots \ldots \ldots \ldots(\mathrm{A}-2) \\
\therefore \quad & Q_{\mathrm{I}}=Q_{\mathrm{II}} \ldots \ldots \ldots \ldots \ldots \ldots \ldots \ldots(\mathrm{A}-3)
\end{aligned}
$$

従つて, 前後 2 船の結びつきに関係なく換算交通量 は一定である。

次に，異なつた大きさで 3 船以上があり，これらの船が 1 船ずつ直列に結びついている場合や 同一の大きさで 3 船以上があり同様に結びついている場合なども以上の考え方がそのまま搪張で きる。

それ故，混合の割合に関係なく換算係数は一定となることが証明される。 